\title{
Computer-aided design of PVR mutants with enhanced binding affinity to TIGIT
}

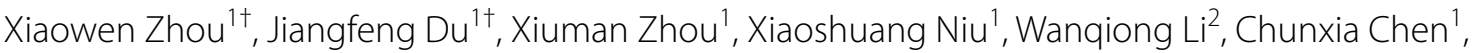 \\ Sifan Lv' ${ }^{1}$, Aijun Wu' ${ }^{1}$ Shanshan Gou ${ }^{1}$, Yixuan Sun ${ }^{1}$, Wenjie Zhai ${ }^{1}$, Lu Qiu' ${ }^{1}$ Yuanming Qi ${ }^{1}$, Wenshan Zhao ${ }^{1{ }^{*+}}$ \\ and Yanfeng Gao ${ }^{1,2^{*}+}$
}

\begin{abstract}
Background: TIGIT, as a novel immune checkpoint molecule involved in T cell and NK cell anergy, could induce the immune tolerance and escape through binding with its ligand PVR. Blockade of TIGIT/PVR is considered as a promising strategy in cancer immunotherapy. However, to facilitate the design of inhibitors targeting TIGIT/PVR, the structural characteristics and binding mechanism still need to be further studied.

Methods: In this study, molecular dynamics (MD) simulations and in silico mutagenesis were used to analyze the interaction between TIGIT and its ligand PVR. Then, PVR mutants were designed and their activities were determined by using TIGIT overexpressed Jurkat cells.

Results: The results suggested that the loops of PVR (CC' loop, $C^{\prime} C^{\prime \prime}$ loop, and FG loop) underwent a large intramolecular rearrangement, and more hydrogen bond crosslinking between PVR and TIGIT were formed during MD simulations. The potential residues for PVR to interact with TIGIT were identified and utilized to predict high affinity PVR mutants. Through the biological activity evaluation, four PVR mutants (pVR $\mathrm{S} 72 \mathrm{~W}$, pVR $\mathrm{S72R}$, pVR G131V and ${ }_{\mathrm{PVR}} \mathrm{S} 132 \mathrm{Q}$ ) with enhanced affinity to TIGIT were discovered, which could elicit more potent inhibitory effects compared with the wild type PVR.

Conclusions: The MD simulations analysis provided new insights into the TIGIT/PVR interaction model, and the identified PVR mutants ( ${ }_{\mathrm{PVR}} \mathrm{S} 72 \mathrm{~W}$, PVR $\mathrm{S} 72 \mathrm{R}$, ${ }_{\mathrm{PVR}} \mathrm{G} 131 \mathrm{~V}$ and ${ }_{\mathrm{PVR}} \mathrm{S} 132 \mathrm{Q}$ ) could serve as new candidates for immunotherapy to block TIGIT/PVR.
\end{abstract}

Keywords: Cancer immunotherapy, TIGIT/PVR, Molecular dynamics, Mutagenesis, Drug design

\section{Background}

Cytotoxic lymphocytes have been involved in the resistance of tumorigenesis and carcinogenesis process through cell-mediated immunity during cancer immunotherapy [1-3]. Cytotoxic lymphocytes, such as natural killer (NK) cells and cytotoxic T lymphocytes (CTLs),

\footnotetext{
*Correspondence: zhaowsh07@zzu.edu.cn; gaoyf29@mail.sysu.edu.cn ${ }^{+}$Xiaowen Zhou and Jiangfeng Du have contributed equally to this work tWenshan Zhao and Yanfeng Gao have jointly supervised this work ${ }^{1}$ School of Life Sciences, Zhengzhou University, Zhengzhou 450001, China

Full list of author information is available at the end of the article
}

express regulatory receptors including co-stimulatory and co-inhibitory molecules, and these molecules coordinate to precisely regulate the function of cytotoxic lymphocytes [4-7]. Co-inhibitory molecules have been involved in mediating immune tolerance and escape, leading to poor therapeutic efficacy in tumor treatment [8-12].

TIGIT, with a full name of $\mathrm{T}$ cell immunoglobulin and ITIM domain (also known as WUCAM, Vstm3 or VSIG9), is an immunosuppressive receptor. TIGIT belongs to poliovirus receptor (PVR)/nectin family and is widely expressed on $\mathrm{NK}$ cells, $\mathrm{CD} 8^{+} \mathrm{T}$ cells, $\mathrm{CD} 4^{+}$ original author(s) and the source, provide a link to the Creative Commons licence, and indicate if changes were made. The images or other third party material in this article are included in the article's Creative Commons licence, unless indicated otherwise in a credit line to the material. If material is not included in the article's Creative Commons licence and your intended use is not permitted by statutory regulation or exceeds the permitted use, you will need to obtain permission directly from the copyright holder. To view a copy of this licence, visit http://creativecommons.org/licenses/by/4.0/. The Creative Commons Public Domain Dedication waiver (http://creativeco mmons.org/publicdomain/zero/1.0/) applies to the data made available in this article, unless otherwise stated in a credit line to the data. 
T cells and Tregs cells [13-17]. Until now, the identified ligands of TIGIT contain CD155 (also known as PVR or nectin-like 5), CD112 and CD113 [15, 18, 19]. Among these ligands, PVR exhibited a higher affinity with TIGIT compared with CD112 and CD113 [19, 20]. PVR is mainly expressed on dendritic cells (DCs), $T$ cells, B cells, macrophages and all kinds of tumor cells [14, 21-24]. Engagement of TIGIT with PVR has been involved in modulating the cytokine production of DCs and facilitating the polarization of pro-inflammatory M1 macrophages into anti-inflammatory M2 macrophages, which in turn lead to the inhibition of effector $\mathrm{T}$ cells and NK cells activation [13, 25-27]. The roles of PVR on normal cells are to prevent excessive immune cells activation and sustain immune homeostasis $[25,28]$. However, tumor cells evade immune surveillance and induce $\mathrm{T}$ cells and NK cells exhaustion by overexpressing PVR [29-31]. Blocking TIGIT-PVR interaction can restore immune exhaustion of T cells and NK cells [27, 32]. Therefore, the development of TIGIT/PVR inhibitors may have potentials in cancer immunotherapy. Antibodies targeting TIGIT/PVR pathway have achieved good clinical results in cancer treatment, as so far six TIGIT-targeting antibodies were under pre-clinical or clinical trials [33, 34].

However, some intrinsic adverse effects of antibody drugs, such as off-target effects, poor tissue penetration and Fc-effector functions, could deplete lymphocytes, which limit the application of antibodies in cancer treatment $[35,36]$. Therefore, the development of other types of drugs targeting TIGIT/PVR pathway is essential for cancer intervention and treatment. Studies have shown that engineered protein drugs targeting immune checkpoint molecules can avoid the disadvantages of antibodies and exhibit better antitumor efficacy [37, 38]. We reported that blockade of TIGIT/PVR by peptide could elicit strong tumor tissue penetration ability and antitumor immune response, even in anti-programmed cell death protein 1 (PD-1) resistant tumor model [39]. As the important role of TIGIT/PVR pathway in regulating the function of the immune cells, it's essential to develop alternative protein drugs targeting the TIGIT/PVR pathway to use individually and in combination with other treatment methods to improve the therapeutic efficacy.

The structure of TIGIT in complex with its ligand PVR has been resolved. It has been shown that both TIGIT and PVR possess three domains: extracellular domain, transmembrane region and cytoplasmic domain, and the extracellular domain has a series of glycosylation sites (Additional file 1: Fig. S1a-d). The extracellular domain of PVR is composed of D1, D2, and D3 domain, and D1 domain of PVR plays an important role in interacting with TIGIT to deliver the inhibitory signals [40]. A series of crystal structures of the extracellular domain of TIGIT and PVR was reported by using X-ray diffraction and electron microscopy (Table 1). These findings facilitate computer-aided drug design using molecular dynamics simulations for molecules which can regulate the TIGIT pathway.

In this study, we used molecular dynamics (MD) simulations to study the interaction between TIGIT and PVR based on the resolved crystal structure (PDBID: 3UDW). We analyzed the structural moment, atomic dynamics of PVR and variations of residual pairs, which helps to identify several novel residues of PVR that potentially bind to TIGIT. Through In silico mutagenesis and cell assay with flow cytometry, we successfully predicted high affinity PVR mutants, and measured the binding affinity of the mutants and the effects of mutants on TIGIT overexpressed Jurkat cells. Finally, we identified several high affinity PVR mutants ${ }_{P V R}$ S72W, ${ }_{P V R}$ S72R, ${ }_{P V R}$ G131V, and ${ }_{\mathrm{PVR}} \mathrm{S} 132 \mathrm{Q}$ ) with more potent inhibitory effects on TIGIT overexpressed Jurkat cells. The MD simulations of TIGIT/PVR complex may help us to understand the binding mechanism of PVR with TIGIT, and the high affinity mutants may serve as start points for the development of TIGIT-PVR inhibitors.

\section{Methods}

\section{Cell culture}

Human embryonic kidney 293 cells (HEK-293) were cultured in Dulbecco's Modified Eagle's Medium (DMEM) (GIBCO, Grand Island, USA) containing 10\% Fetal Bovine Serum (FBS) (Biological Industries, USA), 100 U/ $\mathrm{mL}$ penicillin/streptomycin (Solarbio, China). Jurkat cell line and $\mathrm{CHO}-\mathrm{K} 1$ cell line were cultured in RPMI 1640 medium (GIBCO, Grand Island, USA) supplemented with $10 \% \mathrm{FBS}$, penicillin and streptomycin. All the cell lines were maintained in a humidified condition of $5 \%$ $\mathrm{CO}_{2}$ and $95 \%$ air.

\section{Molecular dynamics simulations}

The 3D structures of hPVR alone and the PVR/TIGIT complex were retrieved from crystal structures with a PDBID of 3UDW, respectively. The 3D structures were processed by GROMACS (Version 4.6) by using OPLS/ AA force field. The processed proteins were then separately solvated in two simulation systems, which were made by water cubic box with SPC water model and periodic boundary conditions $(\mathrm{PBC}=1.0 \mathrm{~nm}$ ) were selected. The solvated systems were neutralized with sodium ions at the physiological conditions. The molecular dynamics simulations in our study were performed in three steps. The structures were firstly relaxed through energy minimization $(E M)$. The potential energy $\left(E_{p o t}\right)$ was negative on the order of $10^{-5}-10^{-6}$ and the maximum force $\left(\mathrm{F}_{\max }\right)$ was less than $1000 \mathrm{~kJ} / \mathrm{mol} / \mathrm{nm}$. Next, the solvent and ions 
Table 1 Specific information for the crystal structure of hPVR extracellular domain

\begin{tabular}{|c|c|c|c|c|c|c|c|c|}
\hline NO & PDBID & Organism(s) & Method & Resolution $(\AA)$ & R-value & PVR length & Notations & Journal \\
\hline 1 & $3 \cup R O$ & Homo Sapiens & X-ray Diffraction & 3.5 & 0.305 & V30-Y242(213) & $\begin{array}{l}\text { N105D, N120S, } \\
\text { N188Q, N218Q, } \\
\text { N237S }\end{array}$ & PNAS, 2008 \\
\hline 2 & $4 \mathrm{FQP}$ & Homo Sapiens & X-ray Diffraction & 3.6 & 0.248 & D28-P333(306) & 0 & $\begin{array}{l}\text { Nat Struct Mol } \\
\text { Biol,2012 }\end{array}$ \\
\hline 3 & 3UDW & Homo Sapiens & X-ray Diffraction & 2.9 & 0.251 & D28-A143 (116) & 0 & PNAS,2012 \\
\hline 4 & 1DGI & $\begin{array}{l}\text { Homo sapiens, } \\
\text { Human poliovirus } 1\end{array}$ & Electron Microscopy & 22 & - & D28-V329(302) & 0 & PNAS,2000 \\
\hline 5 & 1NN8 & $\begin{array}{l}\text { Homo sapiens, } \\
\text { Human poliovirus } 1 \\
\text { Mahoney }\end{array}$ & Electron Microscopy & 15 & - & D28-V329(302) & 0 & J. Virol,2003 \\
\hline 6 & 3EPF & $\begin{array}{l}\text { Homo sapiens, Polio- } \\
\text { virus type } 2 \text { strain } \\
\text { Lansing }\end{array}$ & Electron Microscopy & 9 & - & V30-Y242(213) & $\begin{array}{l}\text { N105D, N120S, } \\
\text { N188Q, N218Q, } \\
\text { N237S }\end{array}$ & PNAS,2008 \\
\hline 7 & 3EPD & $\begin{array}{l}\text { Homo Sapiens, } \\
\text { Human poliovirus } 3\end{array}$ & Electron Microscopy & 9 & - & V30-Y242(213) & $\begin{array}{l}\text { N105D, N120S, } \\
\text { N188Q, N218Q, } \\
\text { N237S }\end{array}$ & PNAS,2008 \\
\hline 8 & 3EPC & $\begin{array}{l}\text { Homo sapiens, } \\
\text { Human poliovirus } 1 \\
\text { Mahoney }\end{array}$ & Electron Microscopy & 8 & - & V30-Y242(213) & $\begin{array}{l}\text { N105D, N120S, } \\
\text { N188Q, N218Q, } \\
\text { N237S }\end{array}$ & PNAS,2008 \\
\hline 9 & $3 J 9 F$ & $\begin{array}{l}\text { Homo sapiens, } \\
\text { Human poliovirus } 1 \\
\text { Mahoney }\end{array}$ & Electron Microscopy & 9 & - & D28-A143 (116) & 0 & J. Virol,2015 \\
\hline 10 & $3 J 8 \mathrm{~F}$ & $\begin{array}{l}\text { Homo sapiens, } \\
\text { Human poliovirus } 1 \\
\text { Mahoney }\end{array}$ & Electron Microscopy & 3.7 & - & D28-P333(306) & 0 & J. Virol,2015 \\
\hline
\end{tabular}

around the protein were equilibrated via two simulation phases. At the first phase, the systems were restrained under an NVT ensemble (constant Number of particles, Volume, and Temperature) and the Verlet scheme was selected for $1 \mathrm{~ns}$ simulation with the temperature of the system reaching a plateau at $310 \mathrm{~K}$. At the second phase, equilibration of pressure was conducted under an NPT ensemble (constant Number of particles, Pressure, and Temperature) for $1 \mathrm{~ns}$ simulation with the pressure set to 1 bar. The Parrinello-Rahman baroslat was used to control the pressure and all bonds involving hydrogen atoms were constrained with the LINCS algorithm during the equilibration procedure. Finally, the position restraints were then released and a production run of 50 ns were performed, where the time step were set to $2 \mathrm{fs}$.

\section{Virtual alanine and residue scanning mutagenesis}

The alanine scanning mutagenesis sequentially mutated each residue of PVR at a time to alanine and the binding energy for each mutant was calculated. Residue Scanning, also known as site-directed mutagenesis, was used to successively mutate important residues of PVR to 20 natural amino acids. In this study, Molecular operating environment (MOE) software (version 2018) was used to performed all the calculation and one site mutation was taken out for the mutagenesis. The calculations were performed by using Amber10 force field and low-mode simulation was used to generate mutants' conformation with a maximum of 30 . MM/GBVI scoring function was used to calculate the binding energy between TIGIT and PVR mutants.

\section{Expression of TIGIT, PVR and the mutants}

The full-length human PVR and human TIGIT was cloned into the pLVX-Puro vector for constructing PVR mutants and functional experiments. All mutants were acquired under site-directed mutagenesis by using a QuickChange mutagenesis kit (Thermo Fisher, USA) and ensured via DNA sequencing. Transfections of plasmids into CHO-K1 or Jurkat cell line were carried out with PowerTrans293 ${ }^{\mathrm{TM}}$ (Sixiang Biological Inc., China) according to the manufacturer's instructions. The cells stably expressing PVR, PVR mutants or TIGIT were ascertained by fluorescent-activated cell sorting (FACS) Caliber flow cytometry, and the cells stably expressing PVR and PVR mutants were next identified using PVR antibody (A5753, ABclonal) by western blotting.

\section{Cell staining analysis}

For cell staining, the Fc-fused protein of human TIGIT (Sino Biological Inc., China) were serially diluted from 120 to 1.875 nM. CHO-K1 cells expressing WT PVR 
or PVR mutants were suspended in phosphate buffered saline (PBS) and incubated with hTIGIT-Fc protein for $30 \mathrm{~min}$ at $4{ }^{\circ} \mathrm{C}$. After incubating with hTIGIT-Fc protein, cells were stained with APC conjugated anti-human IgG Fc (HP6017, Biolegend, USA) for $30 \mathrm{~min}$ at $4{ }^{\circ} \mathrm{C}$. Then, CHO-K1-PVR and CHO-K1-mutants was washed in FACS buffer (PBS with 2\% FBS) and analyzed by FACS Caliber flow cytometry (BD Bioscience, USA). The cells incubated only with PE conjugated human Fc antibody were regarded as the negative controls. The mean fluorescence intensity (MFI) was used to analyze binding affinity of WT and mutant PVR to its ligand TIGIT.

\section{Co-culture assay}

CHO-K1, CHO-K1-hPVR and CHO-K1-mutant cells were seeded into 24 well plates at $1 \times 10^{5}$ cells/well, respectively. Jurkat-hTIGIT cells $\left(2 \times 10^{5}\right.$ cells/well $)$ were co-cultured with CHOK1, CHOK1-hPVR or CHOK1-mutant cells in the presence of $1 \mu \mathrm{g} / \mathrm{mL}$ anti-human CD3 and $0.5 \mu \mathrm{g} / \mathrm{mL}$ anti-human CD28 for $48 \mathrm{~h}$ at $37{ }^{\circ} \mathrm{C}$. The protein transport inhibitor (eBioscience) were added at the last $4 \mathrm{~h}$ before the end of co-culture. For cell staining, Jurkat-hTIGIT cells collected after co-culture were incubated with anti-human TIGIT PE (MBSA43, eBioscience) for $30 \mathrm{~min}$ at $4{ }^{\circ} \mathrm{C}$ and then fixated and permeabilized. Afterwards, permeabilized cells were stained with anti-human IL-2 APC (MQ1-17H12, Belegend) or isotype control for $30 \mathrm{~min}$ at $4{ }^{\circ} \mathrm{C}$. Jurkat cells was washed in FACS buffer (PBS with 2\% FBS) for flow cytometry analysis.

\section{Statistical analysis}

For binding and coculture assay, statistical differences were analyzed by GraphPad Prism 7.04. Statistical significance among different groups was calculated by Student's $t$-test. For correlation analysis, the data were calculated by $\mathrm{R}$ language. The Pearson product-moment correlation coefficient represented correlation between protein expression and binding affinity. The statistically significant values were considered as follows: ${ }^{*} P<0.05$, *** $P<0.01$, and ${ }^{* * * *} P<0.001$. Values of $P<0.05, P<0.01$, and $P<0.001$ were considered as statistically significant.

\section{Results}

\section{Structural dynamics and hydrogen bond crosslinking of PVR}

The structural properties of TIGIT/PVR complex and PVR bound to poliovirus were summarized (Table 1), and crystal structure of 3UDW was chosen based on the resolved resolution, R-value, and mutation sites introduced in the crystal structure to study the binding of PVR and TIGIT. To further elucidate the interaction between human PVR and human TIGIT as well as structural dynamics at the atomic level, 50-ns MD simulations were performed for two systems (hPVR apo and hPVR bound states) under the physiological conditions in which the effects of force field, water, temperature and pressure were well considered. The root mean square deviation (RMSD) calculations were monitored during MD simulations. The RMSD curves of the two trajectories gradually reached to the equilibrium state, indicating that the PVR molecules attained a structurally stable state (Fig. 1a). Therein, the PVR in the bound state showed few fluctuations than PVR in the apo state, indicating that the conformation of PVR in complexed with TIGIT was more stable than that in apo state (Fig. 1a). The PVR in the apo state fluctuated greatly in 30-40 ns and then reached a stable state, which implied that the PVR in the apo state went through momentous structural rearrangements during the MD simulations (Fig. 1a). The averaged structure after 50-ns MD simulations was superimposed to the relevant crystal structure (PDBID: 3UDW) (Fig. 1b), and the results indicated that there were more obvious changes on the loops near the TIGIT binding interface, but not the beta-sheets at the interface between PVR and TIGIT (Fig. 1b). Hereafter, the interaction networks between crystal structure and the averaged structure were analyzed to study whether the MD simulations could indicate more potential residues for TIGIT interaction (Fig. 1c, d). Residues S62, Q63, S74, H79, Q80, P84, S85, T127, P129, S132 in PVR protein were involved in TIGIT binding based on the crystal structure, while the contact residues in PVR were H60, S62, Q63, G73, S74, Q82, P84, V126, P129, G131, S132 after the MD simulations (Fig. 1c, d). The MD averaged conformation showed that residues H60, G73, Q82, V126 and G131 in PVR generated hydrophobic interaction to TIGIT, which were not observed from the crystal structure.

\section{Atomic dynamics of PVR in different states}

The residual fluctuations of PVR in apo and ligand bound states were analyzed. During the 50-ns MD simulations, root mean square fluctuation (RMSF) values of each residue were calculated and the results indicated that the residues in apo PVR was more flexible than that in the TIGIT bound PVR (Fig. 2a). The RMSF values of the residues such as G42, N55, G70, S72, and S89 were significantly different between the apo and bound state, and these residues, especially N72, were more flexible in the apo state (RMSF $>2 \AA$ ) than in bound state (RMSF $<0.8 \AA$ ) (Fig. $2 \mathrm{a}$ ). The residues at the interface were rigid and the residues at PVR BC loop, CC' loop, CC" loop, $C^{\prime \prime} \mathrm{D}$ loop, and FG loop which were adjacent to the interface were relatively more flexible (Fig. 2a and Additional file 1: Fig. S1d). The comparison between apo PVR and TIGIT bound 

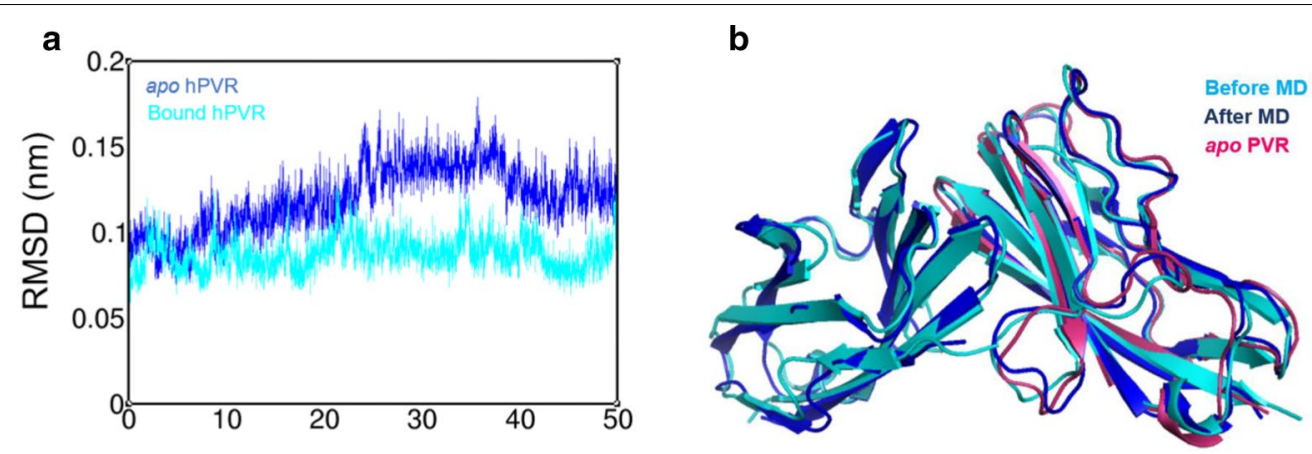

Simulation times (ns)

c

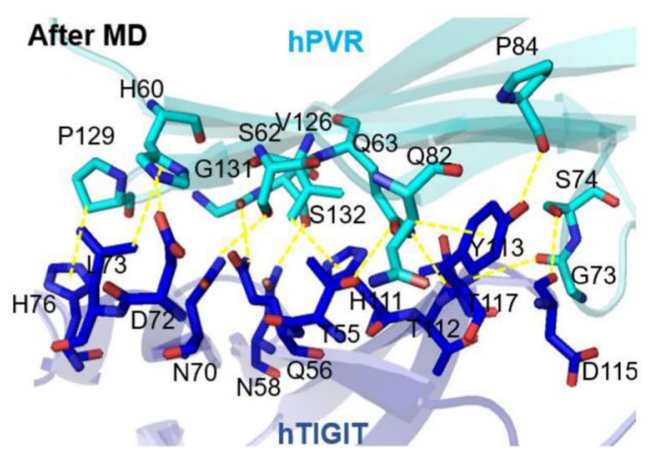

d

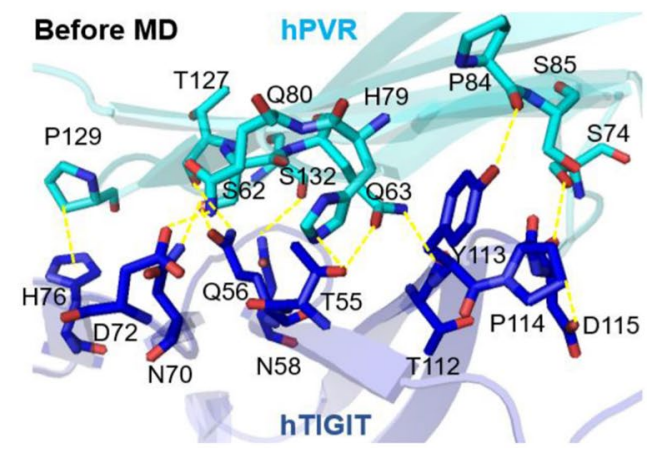

Fig. 1 Structural fluctuations and hydrogen bond network during molecular dynamics simulations. a The root mean square deviation (RMSD) of hPVR in apo state (cyan) and in bound state (blue) were considerably stable during MD simulations. The structural fluctuation of the former was slightly larger than that of the latter and the RMSD score remained 0.05 to $0.2 \mathrm{~nm}$. b The averaged structure of hTIGIT/hPVR complex (After MD, show in blue) and hPVR in apo state (apo hPVR, show in warmpink) during the course of simulations, which were aligned to the TIGIT/PVR complex without MD simulations (Before MD, show in cyan). (c, d) Hydrogen bond network between hPVR (cyan) and hTIGIT (blue) in two states were represented by dashed lines

PVR indicated that the orientations of five residues N55, G70, Q82, S89, and F128 in PVR changed at different states (Fig. 2b). MD simulations revealed that the regions including these five residues were in loop motifs (such as $\mathrm{CC}^{\prime}$ loop, $\mathrm{C}^{\prime} \mathrm{C}^{\prime \prime}$ loop, and FG loop) and the five regions which were relatively close to the binding interface underwent a large intra-molecular rearrangement to facilitate the TIGIT binding process. Meanwhile, the hydrogen bonds formed in these regions, such as $\mathrm{BC}$ loop and $\mathrm{C}^{\prime \prime} \mathrm{D}$ loop, were less stable and might be broken to allosterically regulate the conformation of hPVR to interact with TIGIT (Fig. 2c).

Therefore, the residues H60, S72, S74, Q82, P84, and T127 in PVR that are involved in forming the interactions with TIGIT in the loop regions including $\mathrm{BC}, \mathrm{CC}^{\prime}, \mathrm{C}^{\prime} \mathrm{C}^{\prime \prime}$, and FG loop which were adjacent to the binding interface were selected as potential sites for in silico mutagenesis. The residues V61, G73, H79, S85, G131, and S132 which located close to the TIGIT binding residues were also selected as potential sites for in silico mutagenesis. We proposed that mutagenesis at these residual sites were most probably able to improve the binding affinity to TIGIT.

\section{Distance variations of residue pairs during simulations}

In order to study the residues that are involved in the process of TIGIT/PVR interactions, we measured the distance changes of the amino acid pairs which either contributed to hydrogen bond formation or Van der Waals interactions during MD simulations. The residue in the hPVR was labelled in the front of the residue pair, and the residue in the hTIGIT was marked in the back. During 50-ns MD simulations, the distance of a few amino acid pairs changed slightly and stayed in a relatively stable state, and large fluctuations have been detected in some amino acid pairs (Fig. 3). The residue pairs for the interactions which were crucial for TIGIT binding had a stable distance during the MD simulations (such as ${ }_{\mathrm{PVR}}{ }^{\mathrm{S} 74-}{ }_{\mathrm{TIGIT}} \mathrm{P} 114 / \mathrm{D} 115 / \mathrm{G} 116$, $_{\mathrm{PVR}} \mathrm{S} 85$ -

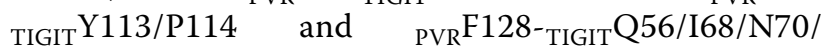
L73) (Fig. 3). The distances between the residual pairs 


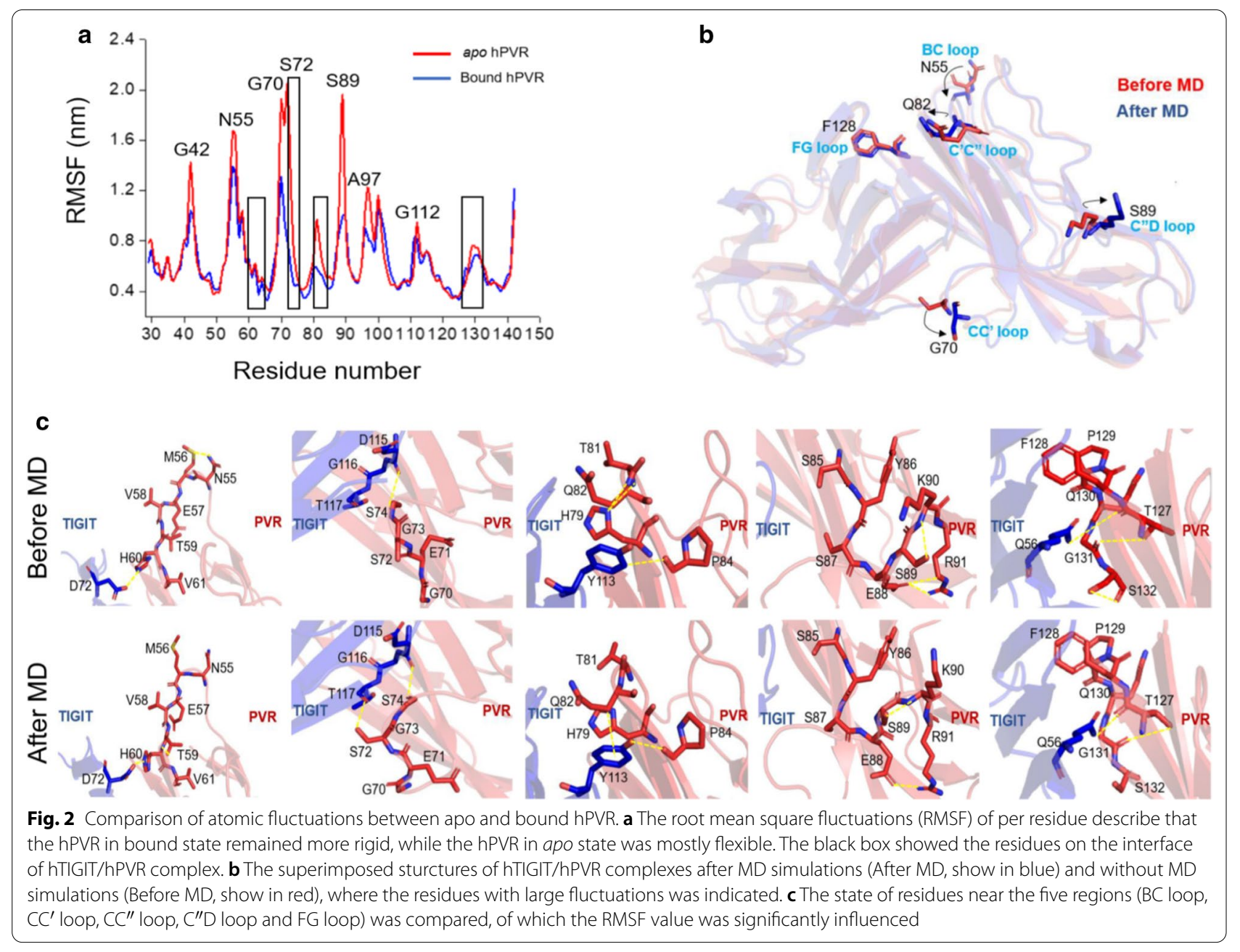

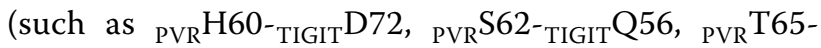

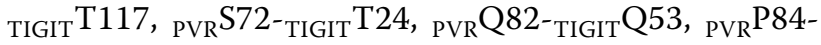
TIGITY113, ${ }_{\text {PVR }}$ S87- ${ }_{\text {TIGIT }}$ D115, ${ }_{\text {PVR }}$ G131- ${ }_{\text {TIGIT }}$ L65, ${ }_{\mathrm{PVR}} \mathrm{S} 132$ TIGIT $_{\mathrm{T}}$ 58, and ${ }_{\mathrm{PVR}} \mathrm{S} 132$ - $_{\mathrm{TIGIT}} \mathrm{H} 111$ ) exhibited large fluctuations. Considering that the residues with small fluctuations may be crucial for the protein-protein interaction, we decided to mutate the residues with relatively larger fluctuations in PVR in order to facilitate the formation of more stable amino acid pairs with TIGIT (Fig. 3). The residues S72 and S87 on PVR only possessed one interaction to TIGIT and the distance for these interactions varied greatly during MD simulations, therefore we proposed that mutations of the amino acids S72 and S87 of PVR could increase the binding affinity between PVR and TIGIT (Fig. 3). We finally selected the residues with large distance variations for designing the high affinity PVR mutants which may interrupt the formation of wild type of PVR and TIGIT.

\section{hPVR mutants generated by the in silico mutagenesis}

The residues of PVR with potential values obtained by different analysis methods described above were summarized and used to perform virtual alanine scanning and residue mutagenesis. Almost all residues that mutated to alanine (Additional file 2: Table S1) reduced the affinity of PVR with TIGIT and decreased the stability of the protein, which proved that these residues were beneficial to the binding of PVR to TIGIT. Then, these residues were mutated into 20 natural amino acids and 3600 PVR mutants were obtained. The binding energies of PVR mutants to TIGIT were calculated by MM/GBVI scoring function in MOE package. Residues substitution of PVR in the "key" region of PVR ${ }^{127} \mathrm{TFP}^{129}$ [41] were not conducive to the improvement of binding affinity and protein stability. However, amino acids replacement of G131 and S132, near the "key" region of PVR ${ }^{127} \mathrm{TFP}^{129}, \mathrm{~S} 72, \mathrm{~S} 74$, S87 with large distance variations (Fig. 3) and residual dynamics (Fig. 2a) had greater potential to enhance the binding affinity. According to the binding affinity, protein 


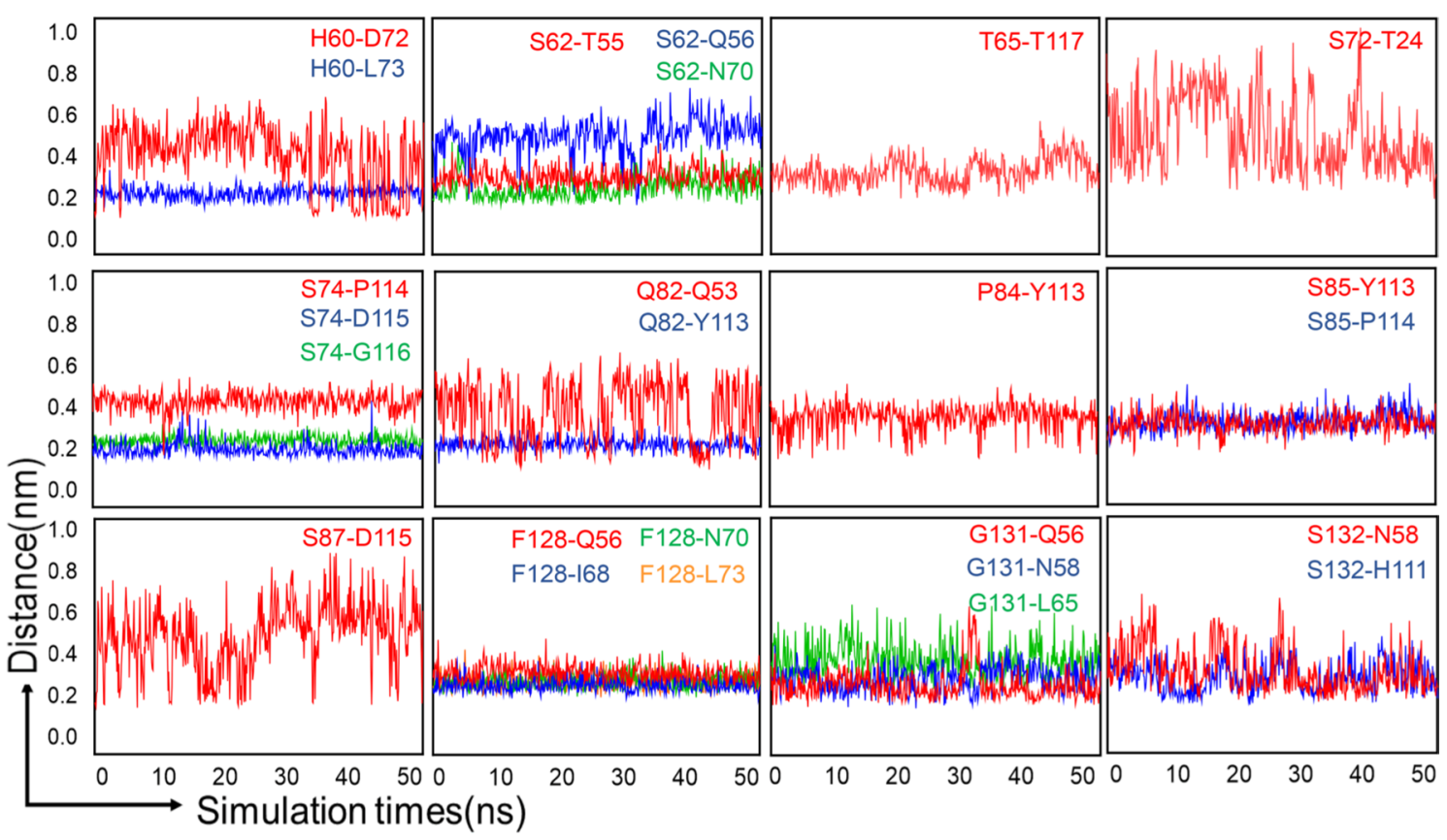

Fig. 3 The distance variations of key residue pairs for hTIGIT/hPVR complex. Graphs showed the distance changes of residue pairs forming hydrogen bonds and Van der Waals distance interactions in TIGIT/PVR complex during MD simulations. The residues in the hPVR are written in the front of the residue pair, the residues in the hTIGIT are written in the back

Table 2 Design of PVR mutants based on key residue positions

\begin{tabular}{lllr}
\hline No. & Mutants & $\boldsymbol{\Delta}$ Affinity $(\mathbf{k c a l} / \mathbf{m o l})$ & $\begin{array}{r}\Delta \text { Stability } \\
(\mathbf{k c a l} / \mathbf{m o l})\end{array}$ \\
\hline 1 & S87W & -6.0533 & -0.4876 \\
2 & S72W & -5.8471 & -0.0612 \\
3 & S72R & -5.8053 & 0.2568 \\
4 & T65E & -4.7483 & 1.0379 \\
5 & G131W & -4.6440 & -0.1364 \\
6 & S74W & -4.5593 & 0.0172 \\
7 & S132R & -4.5511 & 0.2703 \\
8 & G131M & -4.4606 & -0.3685 \\
9 & G131V & -4.2638 & -0.8332 \\
10 & S132Q & -4.2539 & 0.5422 \\
\hline
\end{tabular}

stability and residual fluctuations during MD simulations, 10 mutants S87W, S72W, S72R, T65E, G131W, S74W, S132R, G131M, G131V and S132Q (Table 2) were selected for subsequent measurement of biological functions.

\section{Binding analysis between hPVR mutants and hTIGIT}

Cell-based flow cytometry analysis was carried out to measure the binding affinity of PVR mutants with TIGIT. Ten single-point mutations of PVR including S87W,
S72W, S72R, T65E, G131W, S74W, S132R, G131M, G131V, and S132Q were constructed and the full-length proteins were expressed in $\mathrm{CHO}-\mathrm{K} 1$ cells, respectively. We performed monoclonal screening after constructing stable cell lines of mutants. Cell lines expressing basically consistent PVR mutants were selected for this study (Additional file 1: Fig. S2a). It was found that the mutant T65E merely expressed in a small amount on CHO-K1 cells (Additional file 1: Fig. S2a). Total proteins of the cells stably expressing PVR mutants were extracted, and western blotting was used to detect the expression of PVR protein (Additional file 1: Fig. S2b), which were comparative to those obtained by flow cytometry (Additional file 1: Fig. S2a). The PVR antibody used for western blotting is recombinant fusion protein containing a sequence combining with amino acids 220-345 of human PVR, which indicated that mutations in the residues of PVR D1 domain (corresponding to amino acids 30-143) do not affect the detection of PVR expression by PVR antibodies. These results implied that mutant T65E affected PVR expression.

After the successful construction of the PVR mutant cell lines, we used flow cytometry to measure the binding affinity of PVR mutants (S87W, S72W, S72R, T65E, G131W, S74W, S132R, G131M, G131V or S132Q) to TIGIT-Fc eukaryotic protein. The concentrations of eukaryotic human-TIGIT-Fc were $1.875 \mathrm{nM}, 3.75 \mathrm{nM}$, 
$7.5 \mathrm{nM}, 15 \mathrm{nM}, 30 \mathrm{nM}, 60 \mathrm{nM}$ and $120 \mathrm{nM}$ (Fig. 4a, c). The mutations of S72R, S72W, G131V, S132Q and S74W significantly enhanced the binding of PVR-ecto mutants to TIGIT (Fig. 4a, b).

The mutant G131V significantly enhanced the binding affinity to TIGIT because of the site was replaced by hydrophobic side chain (Fig. 4b). The mutant S132Q presented higher binding affinity with TIGIT and Glutamine (Gln) had a longer polar uncharged side chain than serine (Ser), which indicated that lower steric hindrance performed a crucial role in the interaction between PVR and TIGIT (Fig. 4b). It was surprising that the mutants S72R and S72W which changed the polar uncharged Ser (serine) to positively charged Arg (arginine) or hydrophobic Trp (tryptophan) with aromatic group side chains slightly increased their affinity with TIGIT (Fig. 4b). However, the corresponding PVR-ecto mutants which introduced S87W, T65E, G131W, S132R or G131M mutation decreased the binding affinity to TIGIT (Fig. 4c, d). However, mutant T65E exhibited relatively weak binding capacity to TIGIT (Fig. 4d), which might be caused by the low expression level. The relative binding affinity of each mutants was standardized by the binding affinity of the wild type PVR at the concentration of $120 \mathrm{nM}$ (Fig. 4e). The correlation between the binding affinity and the protein expression level of PVR mutants was studied and the $P$ values were greater than 0.05 and $R^{2}$ were less than 0.35 under different TIGIT protein concentrations (Additional file 1: Fig. S3). The results showed no correlation between the binding affinity and the expression level
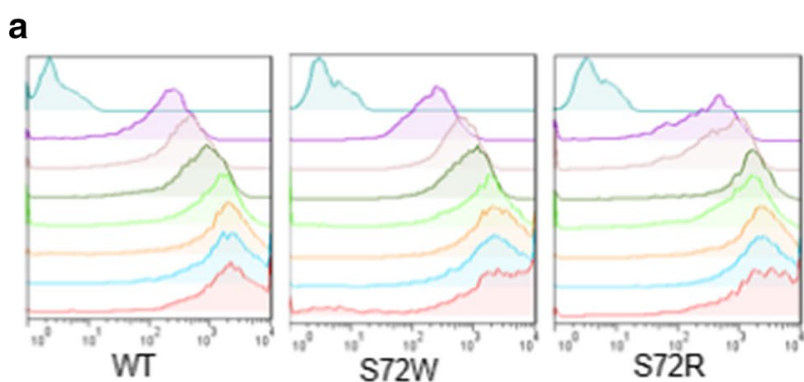

b
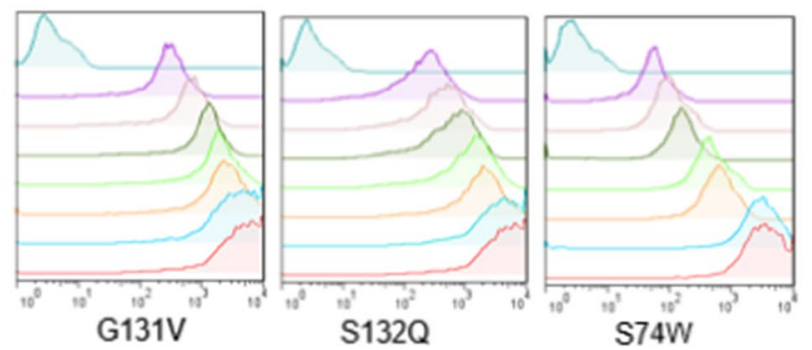

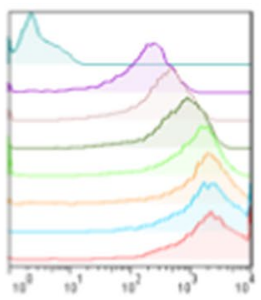

WT

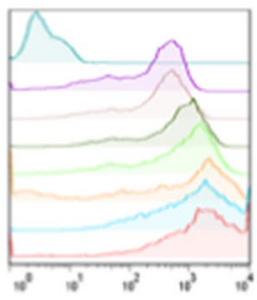

$\mathrm{S} 87 \mathrm{~W}$

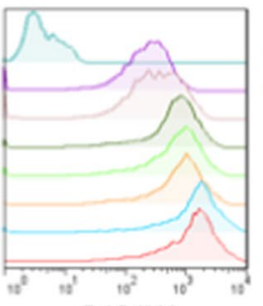

G131W

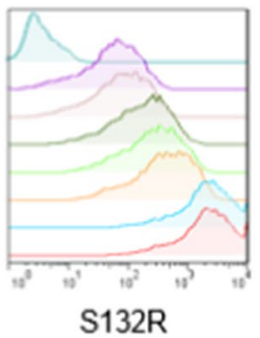

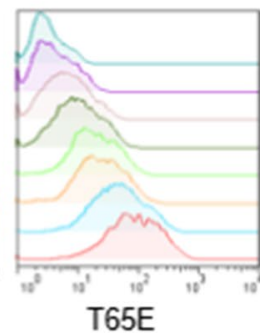

T65E

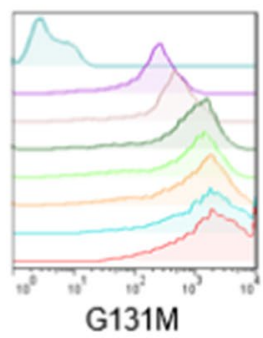

-Anti-Fc $-1.875 \mathrm{nM}-3.75 \mathrm{nM} \quad-7.5 \mathrm{nM}-15 \mathrm{nM}-30 \mathrm{nM}-60 \mathrm{nM}-120 \mathrm{nM}$
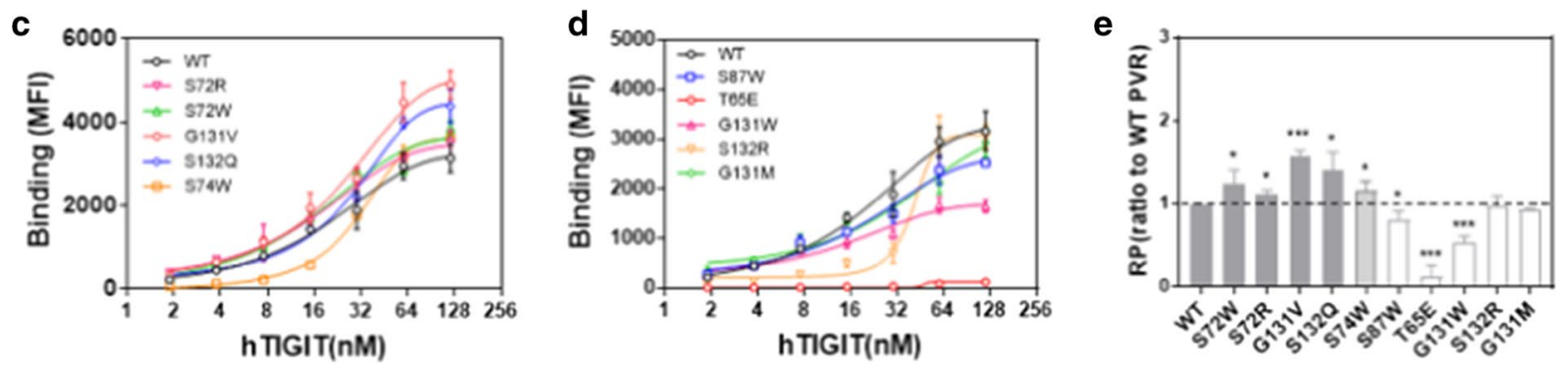

Fig. 4 The binding affinity of hPVR mutants with hTIGIT. a, c Parental CHOK1 cells as well as CHOK1 cells overexpressing WT hPVR and mutant hPVR were used in binding assays. The binding of WT and mutant hPVR with hTIGIT-Fc were assessed by flow cytometry using an anti-human Fc antibody. Representative curves of three independent measurements were shown. $\mathbf{b}$, $\mathbf{d}$ The binding affinity between hPVR mutants and hTIGIT-Fc at various concentrations from 120 to $1.875 \mathrm{nM}$. Graphs showed mean \pm standard error of the mean (SEM) of three independent experiments. e The binding affinity of hPVR mutants were normalized versus WT hPVR (dashed line) at the concentration of $120 \mathrm{nM}$, which was defined as relative hTIGIT binding potency (RP) values of the hPVR mutants. ${ }^{*} P<0.05,{ }^{* *} P<0.01$ and ${ }^{* * *} P<0.001$ by Student's $t$-test 
of PVR mutants, which indicated that the binding affinity of the PVR mutants were mainly depended on the actions of the mutations.

To further verify that there was no correlation between the binding affinity and protein expression, additional experiment was conducted. Firstly, the membrane protein of PVR mutants fused with EGFP were extracted and quantified by the fluorescence value of EGFP to exclude the influence of protein expression on binding affinity. Then the binding affinity of PVR mutants with TIGIT-His eukaryotic protein was identified by microscale thermophoresis (MST) to calculate the $K_{D}$ values of PVR mutants. It was shown that the binding affinities of mutants ${ }_{\mathrm{PVR}} \mathrm{G} 131 \mathrm{~V}\left(\mathrm{~K}_{\mathrm{D}}=0.016 \mu \mathrm{M}\right)$ and ${ }_{\mathrm{PVR}} \mathrm{S} 132 \mathrm{Q}$ $\left(\mathrm{K}_{\mathrm{D}}=0.058 \mu \mathrm{M}\right)$ to TIGIT-His were enhanced about 72-fold and 20-fold, respectively (Additional file 1: Fig. S4a, d-e) compared with wild-type PVR $\left(K_{D}=1.146 \mu \mathrm{M}\right)$. The mutants ${ }_{\mathrm{PVR}} \mathrm{S} 72 \mathrm{~W}\left(\mathrm{~K}_{\mathrm{D}}=0.328 \mu \mathrm{M}\right)$ and ${ }_{\mathrm{PVR}} \mathrm{S} 72 \mathrm{R}$ $\left(\mathrm{K}_{\mathrm{D}}=0.549 \mu \mathrm{M}\right)$ increased their binding affinity to hTIGIT by approximately 4 and 2 times (Additional file 1 : Fig. S4a-c). The results were consistent with that obtained through flow cytometry methods (Additional file 1: Fig. S4a-e, Fig. 4a, c). Also, the mutants ${ }_{\mathrm{PVR}} \mathrm{S} 74 \mathrm{~W},{ }_{\mathrm{PVR}} \mathrm{S} 87 \mathrm{~W}$, PVR T65E, PVR G131W, ${ }_{P V R}$ S132R, and ${ }_{P V R}$ G131M with lower binding affinity consistently impaired the binding (Additional file 1: Fig. S4a, f-k). It was worth mentioned that the fluorescence value of the extracted membrane protein of mutant ${ }_{\mathrm{PVR}} \mathrm{T} 65 \mathrm{E}$ was almost undetectable which was consistent with the previous results of protein expression (Additional file 1: Fig. S2) by flow cytometry and western blotting and it was difficult to detect the binding affinity between these two proteins through MST.

\section{High affinity hPVR mutants decreased IL-2 production}

To further explore whether PVR mutants affect the biological function, we transfected human TIGIT into Jurkat cells which lacked endogenous TIGIT expression and co-cultured Jurkat-TIGIT cells with CHOK1 cells that expressing PVR Wild-Type or mutants. The expression of wild type PVR on CHOK1 cells reduced the proportion of Jurkat-hTIGIT cells which produced IL-2 compared to the parental CHOK1 cell line by using flow cytometry analysis (Fig. 5a, b). The mutants ${ }_{\mathrm{PVR}} \mathrm{S} 72 \mathrm{~W}$, ${ }_{\mathrm{PVR}} \mathrm{S} 72 \mathrm{R}$, ${ }_{P V R} G 131 V$, and ${ }_{P V R} S 132 Q$ induced more potent inhibitory effects of PVR on TIGIT, resulting in a remarkable reduction in the proportion of Jurkat-hTIGIT cells producing IL-2 compared to Jurkat-TIGIT cells co-cultured with wild-type PVR (Fig. 5b), which was consistent with previous results that these mutants showed higher affin-

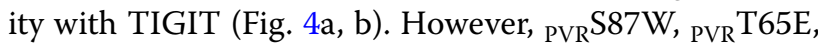
${ }_{\text {PVR }}$ G131W, ${ }_{P V R}$ S74W, ${ }_{P V R}$ S132R, and ${ }_{P V R}$ G131M exhibited a reduced inhibitory effect on IL-2 secretion, and the proportion of Jurkat-TIGIT cells that produced

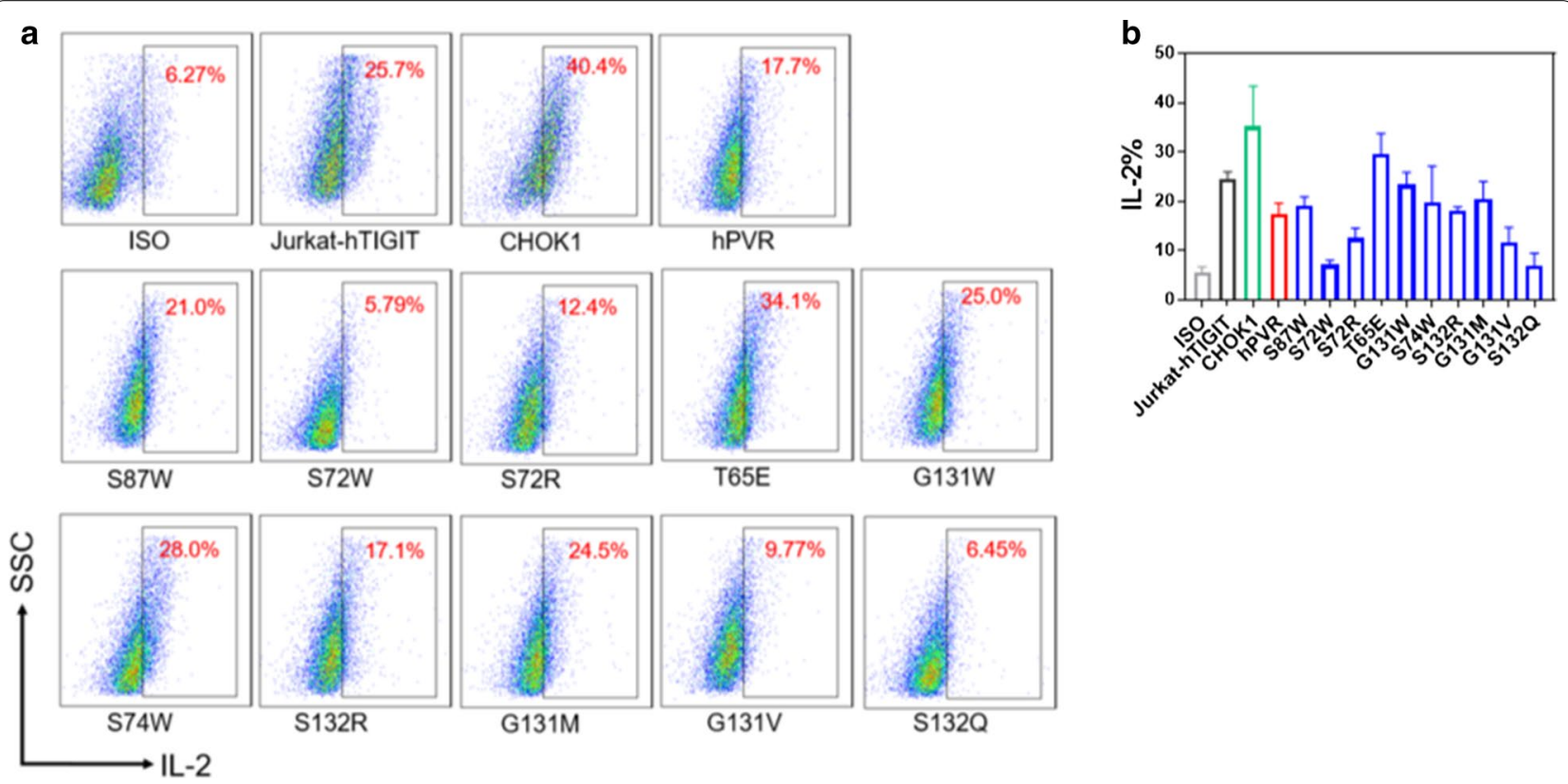

Fig. 5 IL-2 production of Jurkat-hTIGIT cells co-cultured with hPVR mutants. a Jurkat cells overexpressing hTIGIT were co-cultured with CHOK1, CHOK1-hPVR, CHOK1-mutants for 48 h, which was stimulated with $1 \mu \mathrm{g} / \mathrm{mL}$ human anti-CD3 and $0.5 \mu \mathrm{g} / \mathrm{mL}$ human anti-CD28. Protein transport inhibitor was added in the last $4 \mathrm{~h}$. The frequency of IL-2-secreting Jurkat-hTIGIT cells were detected by flow cytometry. Data were representatively independent of three measurements. $\mathbf{b}$ Analysis of the frequency of IL-2-secreting was shown. Graphs showed mean \pm standard error of the mean (SEM) of three independent experiments 
higher level of IL-2 compared to wild-type PVR (Fig. 5b). Among them, ${ }_{\mathrm{PVR}}$ S87W, ${ }_{\mathrm{PVR}}$ T65E, ${ }_{\mathrm{PVR}} \mathrm{G} 131 \mathrm{~W},{ }_{\mathrm{PVR}} \mathrm{S} 132 \mathrm{R}$, and ${ }_{P V R}$ G131M had a weakened inhibitory effect on TIGIT, which were consistent with the results of the aforementioned binding affinity on TIGIT (Fig. 4a, b). The mutant ${ }_{\mathrm{PVR}} \mathrm{S} 74 \mathrm{~W}$ slightly reduced inhibitory effect on TIGIT compared with wild-type PVR, but there was no significant difference (Fig. 5b). The previous affinity results showed that the binding affinity of ${ }_{\mathrm{PVR}} \mathrm{S} 74 \mathrm{~W}$ with TIGIT was lower than that of wild-type PVR at low TIGIT-Fc concentrations, but the affinity of ${ }_{\mathrm{PVR}} \mathrm{S} 74 \mathrm{~W}$ with TIGIT was slightly higher than wild-type PVR when TIGIT-Fc was almost reached the saturated concentration (120 nM) (Fig. 4b). Therefore, the effect of ${ }_{\mathrm{PVR}} \mathrm{S} 74 \mathrm{~W}$ on TIGIT was not different from that of wild-type PVR in the co-culture experiment (Fig. 5b), which might due to the reason that the concentration of PVR interacting with TIGIT did not reach the saturated state. Surprisingly, the co-culture of Jurkat-hTIGIT and CHOK1 cells secreted higher level of IL-2 than that secreted by Jurkat-hTIGIT cells alone (Fig. 5a, b), which might be caused by some stimulatory molecules expressing on $\mathrm{CHOK} 1$ cells.

\section{Discussion}

TIGIT is emerging as a critical immune checkpoint that has been involved in regulating immune effector function. Overexpression of PVR on cancer cells can restrain $T$ cell and NK cell responses because PVR can negatively manipulate TIGIT functions [26, 27, 42]. The structural properties of TIGIT/PVR complex were well studied so far and several antibody drugs targeting TIGIT/PVR pathway have been developed [33, 34, 41]. Studying the dynamic characteristics and binding mechanism at the atomic level between TIGIT and PVR will contribute to the rational discovery and design of PVR inhibitors such as high affinity PVR protein, peptides and small molecules.

The crystal structures of TIGIT and PVR (Table 1) provide atomic details to understand the coordinates of the PVR and the binding mode of the complex, but they lack the dynamic information about the protein. In order to deeply study the flexibility and fluctuation of PVR in different states, we analyzed the overall and atomic level fluctuations of PVR by using MD simulations. The distance variations of important residue pairs for TIGIT/ PVR complex revealed that the residue pairs formed by H60 and S62 on the C sheet (near the BC loop) of PVR, Q82 on the C loop of PVR, S87 on the C"D loop of PVR, and G131 and S132 on the FG loop of PVR underwent large conformational movements (Fig. 3). This is consistent with the results of atomic fluctuations for the corresponding residues (Fig. 2a, c) during MD simulations. Most of these residues with the distance between 4.5 and
$6 \AA$ to hTIGIT molecule are located in the loop region and fluctuated greatly, which suggested that the residues in the loop region play a crucial role for TIGIT/PVR interaction.

The crystal structure of TIGIT bound to PVR revealed that two motifs $\left({ }^{112} \mathrm{TYP}^{114}\right.$ in TIGIT and ${ }^{127} \mathrm{TFP}^{129}$ in PVR) played a crucial role in the interaction of TIGIT and PVR [41]. The "key" residues Y113 in TIGIT and F128 in PVR were respectively inserted into a hydrophobic pocket formed by the engaging molecule. The mutation analysis of the TIGIT/PVR interaction revealed that substitution of Q63 in the (V/I) (S/T) Q motif and F128 in the ${ }^{127} \mathrm{TFP}^{129}$ motif with alanine in PVR reduced the binding affinity with TIGIT [41]. To obtain the energy contribution of the residues in PVR to the TIGIT/PVR interaction, we analyzed some hotspot residues in PVR through molecular dynamics simulation analysis and then performed in silico mutagenesis on hotspot residues. Among them, mutation of Q63 and F128 in PVR to Ala (alanine) affected the binding of TIGIT to PVR and the structural stability of TIGIT/PVR complex, which was consistent with the results of mutation analysis of the TIGIT/PVR interaction. In addition, H60 and V126 on PVR were important to the interaction between TIGIT and PVR, while other hot spot residues but not G131 showed little effects on TIGIT/PVR interaction. The G131A mutant in PVR was not conducive to the binding of TIGIT to PVR, which might be owing to that the steric hindrance generated by the side chain of alanine which affected the function of the "key" region of PVR ${ }^{127} \mathrm{TFP}^{129}$. In this study, hotspot residues were considered as potential candidates for designing high affinity PVR which required an in silico virtual screening and in vitro binding affinity verification.

The conformation of PVR was dynamically changed to facilitate TIGIT interaction. The loops in the protein played critical roles in complex formation. We identified several residues on the TIGIT binding interface or adjacent TIGIT/PVR interface which formed new interface during the MD simulations. These residues mainly located in the loop region near the binding interface and can be identified as potential candidates for mutagenesis in the design of high affinity PVR mutants. To prove our hypothesis, we obtained PVR mutants at these sites and then expressed the mutants on CHOK1 cells. Some mutants $\left(_{\mathrm{PVR}} \mathrm{S} 72 \mathrm{~W},{ }_{\mathrm{PVR}} \mathrm{S} 72 \mathrm{R},{ }_{\mathrm{PVR}} \mathrm{G} 131 \mathrm{~V}\right.$, and $\left.{ }_{\mathrm{PVR}} \mathrm{S} 132 \mathrm{Q}\right)$ in the $\mathrm{CC}^{\prime}$ and FG loop located close to the interface enhanced the binding of PVR to TIGIT. Surprisingly, it was found that ${ }_{\mathrm{PVR}} \mathrm{T} 65 \mathrm{E}$ affected the expression of PVR, which might be due to the fact that charged Glu (glutamate) affected the stability of the molecular structure of PVR. These results are in line with our hypothesis that substitution of residues in the 
loop region closer to the interface contribute to TIGIT/ PVR interaction, and mutations at the interface are not beneficial to obtain high affinity mutants.

TIGIT, DNAM-1 and CD96 could recognize nectin and nectin-like adhesion molecules, such as necl-5 (PVR) and nectin-2. These molecules play important roles for $\mathrm{NK}$ and $\mathrm{T}$ cell function [26, 27, 42-45]. The binding of TIGIT to PVR $\left(\mathrm{K}_{\mathrm{D}}=3.2 \pm 0.4 \mu \mathrm{M}\right)$ [20] was stronger than it to nectin-2 $\left(\mathrm{K}_{\mathrm{D}}=5.8 \pm 0.6 \mu \mathrm{M}\right)[20]$ or CD96/PVR $\left(K_{D}=10.2 \pm 1.1 \mu \mathrm{M}\right)$ [46], which highlights the importance of the TIGIT/PVR pathway in immune regulation. We acquired several high affinity mutants of PVR, which have increased binding affinity to TIGIT and may serve as potential drugs in targeting the TIGIT related pathway. However, the PVR mutants may also bind to other molecules such as TIGIT, DNAM-1 and CD96, therefore the specificity of the mutants should be further considered.

Antibodies targeting TIGIT/PVR pathway have achieved good effects in cancer treatment. The antibody targeting TIGIT using alone or combing other antibodies has achieved significant anti-tumor effects [27]. However, the poor tissue penetration and Fceffector functions limit the development of antibody drugs in cancer treatment. With relatively small molecular weight, PVR mutants without Fc segment might be utilized as protein drugs for cancer treatment, which needs further researches to test the anti-tumor effects of the mutant proteins both in vitro and in vivo. Also, high affinity PVR mutants might be used in combination with multispecific drugs targeting multiple immune pathways to improve the anti-tumor effects.

In summary, we provided a dynamic model for PVR at two different states by applying MD simulations. We also identified several high affinity PVR mutants by using in silico mutagenesis and cell assays. Four PVR mutants ( ${ }_{\text {PVR }}$ S72W, ${ }_{P V R}$ S72R, ${ }_{\text {PVR }}$ G131V and ${ }_{P V R}$ S132Q) enhanced binding affinity of PVR to TIGIT and induced more potent inhibitory effects on TIGIT overexpressed Jurkat cells.

\section{Conclusion}

Molecular dynamics simulations and in silico mutagenesis were applied to study the dynamics of PVR in both states and screen a list of high affinity mutants. The binding affinity of the mutants were measured by cell assay with FACS. Four mutants $\left(_{\mathrm{PVR}} \mathrm{S} 72 \mathrm{~W},{ }_{\mathrm{PVR}} \mathrm{S} 72 \mathrm{R}\right.$, ${ }_{P V R}$ G131V and ${ }_{P V R}$ S132Q) with enhanced affinity for TIGIT could induce more potent inhibitory effects on TIGIT overexpressed Jurkat cells, which could contribute to design new candidates for TIGIT-targeting therapies.

\section{Supplementary Information}

The online version contains supplementary material available at https://doi. org/10.1186/s12964-020-00701-y.

Additional file 1: Figure S1. Protein topology of hTIGIT and hPVR, along with the structure of TIGIT/PVR complex. $(a, b)$ hTIGIT and hPVR contained ectodomain (blue), transmembrane domain (red) and intracellular domain (purple). The glycosylation sites of the extracellular domain were marked with a yellow ball. $(c, d)$ The residue sequences of hTIGIT and hPVR, where the secondary structure $a$-helix and $\beta$-sheet were noted by cyan and yellow shadow respectively, and the residues forming the disulfide bond were represented by red. (e) Model of hTIGIT complexed with hPVR, which was retrieved from heterotetrameric hTIGIT/hPVR complex (PDB ID code 3UDW). The secondary structure and disulfide bond were shown in the same way as above. Figure S2. Stable cell lines of hPVR mutants. (a) CHOK1 cells overexpressing WT and mutant hPVR were stained with antihuman PVR APC. For each histogram, the filled blue histogram with blue line is the hPVR specific antibody and the histogram with red lines is the isotype control. (b) Lysates of CHOK1, CHOK1-hPVR, and CHOK1-mutants were used for western blotting. The blot was developed by chemiluminescence. Figure S3. Relationship between protein expression and binding affinity. Protein expression were normalized versus wild type hPVR cells. Graphs showed the correlation between protein expression and binding affinity When hTIGIT-FC at different concentrations. The Pearson correlation coefficient and P were shown. Figure S4. Binding affinity of PVR mutants fused with EGFP to hTIGIT-His. The membrane protein of PVR mutants fused with EGFP was used to detect the binding affinity with hTIGIT-His. The concentration of TIGIT-His was serially diluted by twofold with $0.000153 \mu \mathrm{M}$ from $25 \mu \mathrm{M}$. The KD values of PVR mutants with hTIGIT-His were shown. Graphs were representative of three independent experiments..

Additional file 2: Table S1. Alanine scanning of important residue positions.

\section{Abbreviations}

TIGIT:T cell immunoglobulin and immunoreceptor tyrosine-based inhibitory motif domain; hTIGIT: Human TIGIT; PVR: Poliovirus receptor; hPVR: Human PVR; MD: Molecular dynamics simulations; MOE: Molecular operating environment; EM: Energy minimization; PBC: Periodic boundary conditions; RMSD: Root mean square deviation; RMSF: Root mean square fluctuation; ${ }_{\mathrm{PVR}} \mathrm{S} 72 \mathrm{~W}$ : The mutation of S72W in PVR.

\section{Acknowledgements}

Not applicable.

\section{Authors' contributions}

YFG and WSZ conceived and designed the projects; XWZ, XMZ and WQL performed cell culture, Cell staining analysis and Co-culture assay; XWZ, XSN, AJW and LQ did mutations and western blotting; JFD, XWZ, SFL and CXC did MD simulations and in silico mutagenesis; XWZ, WSZ and YFG analyzed and interpreted the results; XWZ, WSZ, XMZ, SSG, YXS, WJZ, YMQ and YFG wrote the manuscript. All authors discussed the results and gave final approval of the manuscript.

\section{Funding}

This work was supported by grants from National Natural Science Foundation of China (Nos. 31700677 and U1904147 for W.S.Z., 81822043 and U1604286 for Y.F.G.), the Key Scientific Research Projects of Henan Higher Education Institutions (18A180004 for W.S.Z., 19A180009 for J.F.D.), and Young talent promotiom program of Henan Association for Science and Technology (2019HYTP015 for W.S.Z).

\section{Availability of data and materials}

The datasets used and/or analyzed during the current study are available from the corresponding author on reasonable request.

Ethics approval and consent to participate Not applicable. 


\section{Consent for publication \\ Not applicable.}

\section{Competing interests}

The authors declare that they have no competing interests.

\section{Author details}

1 School of Life Sciences, Zhengzhou University, Zhengzhou 450001, China.

${ }^{2}$ School of Pharmaceutical Sciences (Shenzhen), Sun Yat-Sen University, Shenzhen 518107, China.

Received: 31 July 2020 Accepted: 26 December 2020

Published online: 08 February 2021

\section{References}

1. Bryceson $\mathrm{YT}$, March ME, Ljunggren HG, Long EO. Activation, coactivation, and costimulation of resting human natural killer cells. Immunol Rev. 2006;214:73-91. https://doi.org/10.1111/j.1600-065X.2006.00457.x.

2. Cerwenka A, Lanier LL. Natural killer cells, viruses and cancer. Nat Rev Immunol. 2001:1:41-9. https://doi.org/10.1038/35095564.

3. Liu J, Zhang S, Tan S, Zheng B, Gao GF. Revival of the identification of cytotoxic T-lymphocyte epitopes for immunological diagnosis, therapy and vaccine development. Exp Biol Med (Maywood). 2011;236:253-67. https://doi.org/10.1258/ebm.2010.010278.

4. Martinet $L$, Smyth MJ. Balancing natural killer cell activation through paired receptors. Nat Rev Immunol. 2015;15:243-54. https://doi. org/10.1038/nri3799.

5. Chen L, Flies DB. Molecular mechanisms of T cell co-stimulation and co-inhibition. Nat Rev Immunol. 2013;13:227-42. https://doi.org/10.1038/ nri3405.

6. Schnell A, Bod L, Madi A, Kuchroo VK. The yin and yang of co-inhibitory receptors: toward anti-tumor immunity without autoimmunity. Cell Res. 2020. https://doi.org/10.1038/s41422-020-0277-x.

7. Zhai W, Zhou X, Wang H, Li W, Chen G, Sui X, et al. A novel cyclic peptide targeting LAG-3 for cancer immunotherapy by activating antigen-specific CD8+ T cell responses. Acta Pharm Sin B. 2020. https://doi.org/10.1016/j. apsb.2020.01.005

8. Fessas P, Possamai LA, Clark J, Daniels E, Gudd C, Mullish BH, et al. Immunotoxicity from checkpoint inhibitor therapy: clinical features and underlying mechanisms. Immunology. 2020;159:167-77. https://doi. org/10.1111/imm.13141.

9. Crispen PL, Kusmartsev S. Mechanisms of immune evasion in bladder cancer. Cancer Immunol Immunother. 2020;69:3-14. https://doi. org/10.1007/s00262-019-02443-4.

10. Restifo NP, Smyth MJ, Snyder A. Acquired resistance to immunotherapy and future challenges. Nat Rev Cancer. 2016;16:121-6. https://doi. org/10.1038/nrc.2016.2.

11. Zhai W, Zhou X, Du J, Gao Y. In vitro assay for the development of small molecule inhibitors targeting PD-1/PD-L1. Methods Enzymol. 2019;629:361-81. https://doi.org/10.1016/bs.mie.2019.05.051.

12. Zhang S, Liang W, Luo L, Sun S, Wang F. The role of T cell trafficking in CTLA-4 blockade-induced gut immunopathology. BMC Biol. 2020;18:29. https://doi.org/10.1186/s12915-020-00765-9.

13. Yu X, Harden K, Gonzalez LC, Francesco M, Chiang E, Irving B, et al. The surface protein TIGIT suppresses T cell activation by promoting the generation of mature immunoregulatory dendritic cells. Nat Immunol. 2009;10:48-57. https://doi.org/10.1038/ni.1674.

14. Boles KS, Vermi W, Facchetti F, Fuchs A, Wilson TJ, Diacovo TG, et al. A novel molecular interaction for the adhesion of follicular CD4 T cells to follicular DC. Eur J Immunol. 2009;39:695-703. https://doi.org/10.1002/ eji.200839116

15. Stanietsky N, Simic H, Arapovic J, Toporik A, Levy O, Novik A, et al. The interaction of TIGIT with PVR and PVRL2 inhibits human NK cell cytotoxicity. Proc Natl Acad Sci USA. 2009;106:17858-63. https://doi.org/10.1073/ pnas.0903474106

16. Levin SD, Taft DW, Brandt CS, Bucher C, Howard ED, Chadwick EM, et al. Vstm3 is a member of the CD28 family and an important modulator of T-cell function. Eur J Immunol. 2011;41:902-15. https://doi. org/10.1002/eji.201041136.
17. Manieri NA, Chiang EY, Grogan JL. TIGIT: a key inhibitor of the cancer immunity cycle. Trends Immunol. 2017;38:20-8. https://doi. org/10.1016/j.it.2016.10.002.

18. Sanchez-Correa B, Valhondo I, Hassouneh F, Lopez-Sejas N, Pera A, Bergua JM, et al. DNAM-1 and the TIGIT/PVRIG/TACTILE axis: novel immune checkpoints for natural killer cell-based cancer immunotherapy. Cancers (Basel). 2019. https://doi.org/10.3390/cancers 11060877.

19. Satoh-Horikawa K, Nakanishi H, Takahashi K, Miyahara M, Nishimura $M$, Tachibana $K$, et al. Nectin-3, a new member of immunoglobulinlike cell adhesion molecules that shows homophilic and heterophilic cell-cell adhesion activities. J Biol Chem. 2000;275:10291-9. https://doi. org/10.1074/jbc.275.14.10291.

20. Deuss FA, Gully BS, Rossjohn J, Berry R. Recognition of nectin-2 by the natural killer cell receptor T cell immunoglobulin and ITIM domain (TIGIT). J Biol Chem. 2017;292:11413-22. https://doi.org/10.1074/jbc. M117.786483.

21. Mendelsohn CL, Wimmer E, Racaniello VR. Cellular receptor for poliovirus: molecular cloning, nucleotide sequence, and expression of a new member of the immunoglobulin superfamily. Cell. 1989;56:855-65. https://doi.org/10.1016/0092-8674(89)90690-9.

22. Masson D, Jarry A, Baury B, Blanchardie P, Laboisse C, Lustenberger $P$, et al. Overexpression of the CD155 gene in human colorectal carcinoma. Gut. 2001;49:236-40. https://doi.org/10.1136/gut.49.2.236.

23. Casado JG, Pawelec G, Morgado S, Sanchez-Correa B, Delgado E, Gayoso l, et al. Expression of adhesion molecules and ligands for activating and costimulatory receptors involved in cell-mediated cytotoxicity in a large panel of human melanoma cell lines. Cancer Immunol Immunother. 2009;58:1517-26. https://doi.org/10.1007/s00262-009-0682-y.

24. Bevelacqua V, Bevelacqua Y, Candido S, Skarmoutsou E, Amoroso A, Guarneri C, et al. Nectin like-5 overexpression correlates with the malignant phenotype in cutaneous melanoma. Oncotarget. 2012;3:882-92. https://doi.org/10.18632/oncotarget.594.

25. Chen X, Lu PH, Liu L, Fang ZM, Duan W, Liu ZL, et al. TIGIT negatively regulates inflammation by altering macrophage phenotype. Immunobiology. 2016;221:48-55. https://doi.org/10.1016/j.imbio.2015.08.003.

26. Johnston RJ, Comps-Agrar L, Hackney J, Yu X, Huseni M, Yang Y, et al. The immunoreceptor TIGIT regulates antitumor and antiviral CD8(+) T cell effector function. Cancer Cell. 2014;26:923-37. https://doi. org/10.1016/j.ccell.2014.10.018.

27. Zhang Q, Bi J, Zheng $X$, Chen $Y$, Wang $H, W u$ W, et al. Blockade of the checkpoint receptor TIGIT prevents NK cell exhaustion and elicits potent anti-tumor immunity. Nat Immunol. 2018;19:723-32. https:// doi.org/10.1038/s41590-018-0132-0.

28. Takai Y, Irie K, Shimizu K, Sakisaka T, Ikeda W. Nectins and nectin-like molecules: roles in cell adhesion, migration, and polarization. Cancer Sci. 2003;94:655-67. https://doi.org/10.1111/j.1349-7006.2003.tb014 99.x.

29. Sloan KE, Eustace BK, Stewart JK, Zehetmeier C, Torella C, Simeone $M$, et al. CD155/PVR plays a key role in cell motility during tumor cell invasion and migration. BMC Cancer. 2004;4:73. https://doi. org/10.1186/1471-2407-4-73.

30. Gao J, Zheng Q, Xin N, Wang W, Zhao C. CD155, an onco-immunologic molecule in human tumors. Cancer Sci. 2017;108:1934-8. https://doi. org/10.1111/cas.13324.

31. Li XY, Das I, Lepletier A, Addala V, Bald T, Stannard K, et al. CD155 loss enhances tumor suppression via combined host and tumor-intrinsic mechanisms. J Clin Invest. 2018;128:2613-25. https://doi.org/10.1172/ JCl98769.

32. Kucan Brlic P, Lenac Rovis T, Cinamon G, Tsukerman P, Mandelboim O, Jonjic S. Targeting PVR (CD155) and its receptors in anti-tumor therapy. Cell Mol Immunol. 2019;16:40-52. https://doi.org/10.1038/s4142 3-018-0168-y.

33. Solomon BL, Garrido-Laguna I. TIGIT: a novel immunotherapy target moving from bench to bedside. Cancer Immunol Immunother. 2018;67:1659-67. https://doi.org/10.1007/s00262-018-2246-5.

34. April 2, 2020 SITC18: Merck highlights new LAG-3 and TIGIT data. $<$ https://www.fiercebiotech.com/biotech/sitc-merck-highlights-newlag-3-and-tigit-data>

35. Beckman RA, Weiner LM, Davis HM. Antibody constructs in cancer therapy: protein engineering strategies to improve exposure in solid tumors. Cancer. 2007;109:170-9. https://doi.org/10.1002/cncr.22402. 
36. Tabrizi MA, Roskos LK. Preclinical and clinical safety of monoclonal antibodies. Drug Discov Today. 2007;12:540-7. https://doi.org/10.1016/.drudi s.2007.05.010

37. Maute RL, Gordon SR, Mayer AT, McCracken MN, Natarajan A, Ring NG, et al. Engineering high-affinity PD-1 variants for optimized immunotherapy and immuno-PET imaging. Proc Natl Acad Sci USA. 2015;112:E650614. https://doi.org/10.1073/pnas.1519623112.

38. Du J, Qin Y, Wu Y, Zhao W, Zhai W, Qi Y, et al. The design of high affinity human PD-1 mutants by using molecular dynamics simulations (MD). Cell Commun Signal. 2018;16:25. https://doi.org/10.1186/s1296 4-018-0239-9.

39. Zhou X, Zuo C, Li W, Shi W, Zhou X, Wang H, et al. A novel D peptide identified by mirror-image phage display blocks TIGIT/PVR for cancer immunotherapy. Angew Chem Int Ed Engl. 2020. https://doi.org/10.1002/ anie.202002783.

40. Li M, Xia P, Du Y, Liu S, Huang G, Chen J, et al. T-cell immunoglobulin and ITIM domain (TIGIT) receptor/poliovirus receptor (PVR) ligand engagement suppresses interferon-gamma production of natural killer cells via beta-arrestin 2-mediated negative signaling. J Biol Chem. 2014:289:17647-57. https://doi.org/10.1074/jbc.M114.572420.

41. Stengel KF, Harden-Bowles K, Yu X, Rouge L, Yin J, Comps-Agrar L, et al. Structure of TIGIT immunoreceptor bound to poliovirus receptor reveals a cell-cell adhesion and signaling mechanism that requires cis-trans receptor clustering. Proc Natl Acad Sci USA. 2012;109:5399-404. https:// doi.org/10.1073/pnas.1120606109.
42. Kurtulus S, Sakuishi K, Ngiow SF, Joller N, Tan DJ, Teng MW, et al. TIGIT predominantly regulates the immune response via regulatory $T$ cells. J Clin Invest. 2015;125:4053-62. https://doi.org/10.1172/JCl81187.

43. Chan CJ, Martinet L, Gilfillan S, Souza-Fonseca-Guimaraes F, Chow MT, Town L, et al. The receptors CD96 and CD226 oppose each other in the regulation of natural killer cell functions. Nat Immunol. 2014;15:431-8. https://doi.org/10.1038/ni.2850

44. Iguchi-Manaka A, Kai H, Yamashita Y, Shibata K, Tahara-Hanaoka S, Honda $\mathrm{S}$, et al. Accelerated tumor growth in mice deficient in DNAM-1 receptor. J Exp Med. 2008;205:2959-64. https://doi.org/10.1084/jem.20081611.

45. Zhou XM, LiWQ, Wu YH, Han L, Cao XG, Yang XM, et al. Intrinsic expression of immune checkpoint molecule TIGIT could help tumor growth in vivo by suppressing the function of NK and CD8(+) T cells. Front Immunol. 2018;9:2821. https://doi.org/10.3389/fimmu.2018.02821.

46. Deuss FA, Watson GM, Fu Z, Rossjohn J, Berry R. Structural basis for CD96 immune receptor recognition of nectin-like protein-5, CD155. Structure. 2019;27(219-28):e3. https://doi.org/10.1016/j.str.2018.10.023.

\section{Publisher's Note}

Springer Nature remains neutral with regard to jurisdictional claims in published maps and institutional affiliations.
Ready to submit your research? Choose BMC and benefit from:

- fast, convenient online submission

- thorough peer review by experienced researchers in your field

- rapid publication on acceptance

- support for research data, including large and complex data types

- gold Open Access which fosters wider collaboration and increased citations

- maximum visibility for your research: over $100 \mathrm{M}$ website views per year

At BMC, research is always in progress.

Learn more biomedcentral.com/submissions 